\title{
Cinnamon Mouthwash as an Anti-Fungal Agent in Treatment of Diabetic Patients with Chronic Periodontitis
}

\author{
Sheela Gujjari* \\ Department of Dentistry, JSS University, India
}

Submission: February 13, 2018; Published: March 05, 2018

*Corresponding author: Sheela Gujjari, Department of Dentistry, Jagadguru Sri Shivarathreeshwara University, Mysore, India, Tel: 9448836777 , Email: sheelagujjari@gmail.com

\section{Abstract}

The oral cavity contains a phlethora of microorganisms leading to poly microbial biofilms. Oral candidiasis is one of the most well defined fungal infections wherein, Candida interacts with each other and with bacteria in the orral cavity. Candida has been found in the subgingival biofilm of moderate and severe periodontitis. Also, in diabetics, a higher prevalence of Candida has been reported. Due to antibiotic resistance the attention has turned to plants as an alternative therapy to combat candidiasis, of which Cinnamon has been found to have anti-fungal property.

Objective: To evaluate the effect of Cinnamon mouthwash on Candida albicans in Type-2 diabetes with chronic periodontits.

Materials and Methods: 30 patients were divided into 2 groups that are diabetic type II patients with chronic periodontitis (test) and nondiabetic patients with chronic periodontitis (control). Glycosylated haemoglobin, questionnaire regarding duration of diabetes and medications were recorded and exfoliative cytology was carried out to detect candida albicans. Patients with candida albicans positive were taken up for the study. Both groups underwent scaling and root planing. On completion freshly prepared cinnamon mouthwash was dispensed in $100 \mathrm{ml}$ bottles with instruction for usage. At end of 3months exfoliative cytology was done and patients were advised to stop usage of mouthwash one week after cessation of mouthwash patients were recalled for clinical examination and exfoliative cytology.

Results: Candidal carriage was more in diabetics than non diabetics with chronic periodontitis. There was no difference between gender and the candidal carriage was more in patients with longer duration of diabetes over 10 years and severity of candidal carriage was more according to the duration. Candidal carriage was found to be more in uncontrolled diabetics. There was significant reduction in candidal carriage between baseline and 3 weeks in diabetic patients and in non-diabetics. After cessation of mouthwash recolonisation of candida albicans was observed in both the groups.

Conclusion: Results of the study proved the potential of cinnamon as an anti-fungal agent.

Keywords: Cinnamon; Candidial carriage; Chronic periodontitis; Diabetics; Exfoliative Cytology

Abbreviations: DM: Diabetes Mellitus; MIC: Minimum Inhibitory Concentration, PAS: Periodic Acid Stain

\section{Introduction}

Candida albicans is a harmless commensal organism present in $20-40 \%$ of healthy individuals [1]. Diabetes mellitus (DM) has been found to be associated with reduced response of T-cells, neutrophil function and disorders of immunity which makes them more prone to infections such as Candidiasis, Candida albicans being the most prevalent species [2]. The main reservoir for Candida in the oral cavity has found to be the buccal mucosa and tounge. It has also been found to co-aggregate with bacteria in the subgingival biofilm and adhere to the epithelial cells and invade the gingival connective tissue. It is also found in the periodontal pocket of chronic periodontitis patients [3]. Cinnamon being an ancient spice in the kitchen has been found to have multiple medicinal values too. Cinnamomum zeylanicum and Cinnamom cassia are the only two approved medicinal herbs of the genus Cinnamomum. It has been found to have anti-cholesterol, antibacterial as well as anti-fungal property [4]. As there are very few studies to prove the anti-fungal property of cinnamon, this study was done to evaluate the effect of cinnamon as an anti-fungal agent in diabetic Type-2 patients with chronic periodontitis.

\section{Materials and Methods}

Ethical approval was obtained from the Institutional review board ethical committee governing the use of human subjects in clinical trial JSS Dental College and Hospital and affiliated 
institution of Jagadguru Sri Shivarathreeshwara University, Mysore.

The trial was a parallel interventional pilot study conducted over a period of 1 month. The inclusion criteria for study group were Patients above 40 years with clinically healthy oral mucosa, Medical history of type II diabetes mellitus for a minimum period of 1 year irrespective of whether they were on any medication of diabetes or not. Control group consisted of healthy individuals without any systemic illness. Both study and control groups were patients with presence chronic periodontites, who had at least 20 teeth, probing depth $>5 \mathrm{~mm}$ and who were willing to be a part of the study were selected. In both study and control group Candida should be present. Before beginning of the study informed consent was obtained from all the study participants. The diabetics were monitored by the physician and information was obtained regarding type of medication and duration of diabetes. Total of 30 patients were selected based on inclusion and exclusion criteria and were equally divided into study and control groups. In both the groups mucosal scrapings were taken from the dorsum of the tongue and buccal mucosa and sent to Department of Oral Pathology and Microbiology of JSS Dental College and Hospital for Exfoliative cytology to detect the presence of Candida albicans.

\section{Exfoliative Cytology}

Mucosal scrapings were taken from the buccal mucosa with the help of a wet wooden spatula. These scrapings were made into smears on a glass slide with circular motion. The smears were fixed immediately with 95\% ethyl alcohol in a coupling jar. The fixed smears were then stained with PAS (Periodic Acid Stain) reagent. McManus PAS method [5] was used as the staining technique to identify the Candida albicans. Similar procedure was performed for each patient at 0 day, baseline, 3 weeks and at 4 th week. All the slides prepared were blinded.

All the cytological smears were assessed microscopically for the presence of Candida. Screening was done at 100X magnification. The presence of Candida and its forms were observed and confirmed at 400X magnification. Presence of hyphae, yeast, budding yeast, pseudohyphae and branching mycelium were recorded. Based on the form of Candida, present score of 0-4 was given (Table 2) for each slide. The scores were then compared for each case at day 0, 3 weeks and 4 weeks (Table 1).

Table 1: Scoring criteria for Candidal colonization.

\begin{tabular}{|c|c|}
\hline Score & Inference \\
\hline 0 & No evidence of Candida \\
\hline 1 & Presence of yeast and hyphae without budding yeast \\
\hline 2 & Many numbers of yeast, hyphae with budding yeast \\
\hline 3 & $\begin{array}{c}\text { Many numbers of yeast, hyphae with pseudohyphae }<3 \text { in } \\
\text { number }\end{array}$ \\
\hline 4 & $\begin{array}{c}\text { Many numbers of yeast, hyphae with pseudo hyphae }>3 \text { in } \\
\text { number \& branching mycelium }\end{array}$ \\
\hline
\end{tabular}

Table 2: Constituents of Cinnamon.

\begin{tabular}{|c|c|}
\hline Bark & Cinnamldehyde - 65 to 80\% \\
\hline Eugenol - 5 to 10\% & \\
\hline Leaves & Cinnamldehyde - 1 to 5\% \\
\hline Eugenol - 70 to 95\% & Camphor - 60\% \\
\hline Root Bark & Trans - cinnamyl acetate and $\beta$ - \\
caryophyllene
\end{tabular}

The subjects who were detected with the presence of Candida albicans were taken up for the study. The subjects of both the groups then underwent scaling and root planning. Cinnamon was extracted and mouthwash was prepared in JSS College of Pharmacy. The mouthwash was prepared based on the MIC (Minimum Inhibitory Concentration) which was determined in the Microbiology Department of Life Sciences, JSS University. The mouthwash was dispensed in sterilized $100 \mathrm{ml}$ containers.

\section{Preparation of Cinnamon Extract}

An aqueous cinnamon extract was prepared using the Soxhlet technique [6] from the barks of Cinnamomum zylinicum from Kollam district, Kerala as verified by Dr M. N. Naganandini, Assistant Professor, J.S.S College of Pharmacy, Mysore.

\section{Plant Profile}

\section{Habitat}

The spice is derived from the brown bark, which forms quills with longitudinal striations. The plant is native to Sri Lanka, South eastern India, Indonesia, South America, and the West Indies.

\section{Plant Hierarchy:}

Kingdom Plantae - Plants

Subkingdom Tracheobionta - Vascular plants

Superdivision Spermatophyta - Seed plants

Division Magnoliophyta - Flowering plants

Class Magnoliopsida - Dicotyledons

Subclass Magnoliidae

Order Laurales

Family Lauraceae - Laurel family

Genus Cinnamomum Schaeff. - Cinnamon

Species Cinnamomum zylinicum J. Presl - Cinnamon 


\section{Scientific Names}

Cinnamomum zylinicum, Cinnamomum cassia, Cinnamomum zeylanicum, Cinnamomum loureirii

\section{Common Names}

Cinnamon, Cinnamomon, Ceylon cinnamon, Chinese cinnamon, Chinese cassia, Saigon cinnamon

\section{Photochemistry}

One of the most popular spices used worldwide, cinnamon is known for its aromatic fragrance and sweet, warm taste. The spice is derived from the bark of an evergreen tree, which belongs to the family Lauraceae. Mostly cinnamon is used as a spice, cinnamon has great medicinal value. It has been found to be extremely helpful in the treatment of Type 2 diabetes mellitus and insulin resistance. The scientific studies have proved that a variety of biologically active chemicals have been found in Cinnamon which have immense medical potential. It contains a number of compounds, including essential oils that provide the spice's flavor. Other compounds which are present in lesser percentages those are Cinnamic acid, Hydroxyl Cinnamaldehyde, Cinnamyl alcohol, Coumarin, Cinnamyl acetate, Borneol etc (Table 2).

\section{The mouthwash was prepared based on the MIC which was determined in the Microbiology Department of Life Sciences, JSS University}

The MIC was found to be maximum at $0.5 \%$. Using the $0.5 \%$ concentration the mouthwash was formulated. At the end of scaling and root planning the patients were given oral hygiene instructions and were directed to use $10 \mathrm{ml}$ of mouthwash twice daily for $1 \mathrm{~min}$ for a period of 3 weeks. The patients were periodically monitored for any adverse reactions. At the end of 3 weeks clinical examination was done and Candida albicans levels were evaluated. During $4^{\text {th }}$ week mouth wash was not given to patients. At the end of $4^{\text {th }}$ week Candida albicans again evaluated to see the effect of cinnamon mouth wash after cessation.

\section{Results}

(Table 3-10).

Table 3: Comparison of candidal carriage among diabetic and nondiabetic.

\begin{tabular}{|c|c|c|c|c|c|}
\hline Groups & $\begin{array}{c}\text { Mild n } \\
\text { (\%) }\end{array}$ & $\begin{array}{c}\text { Moderate } \\
\text { (\%) }\end{array}$ & $\begin{array}{c}\text { Severe } \\
\text { (\%) }\end{array}$ & $\begin{array}{c}\text { Chi } \\
\text { square } \\
\text { value }\end{array}$ & P value \\
\cline { 1 - 3 } Diabetic & $3(20)$ & $6(40)$ & $6(40)$ & 9 & $0.011(\mathrm{sig})$ \\
\cline { 1 - 2 } $\begin{array}{c}\text { Non- } \\
\text { diabetic }\end{array}$ & & & & & \\
\hline
\end{tabular}

Table 4: Assessment of candidal carriage among diabetics according to duration and age.

\begin{tabular}{|c|c|c|c|c|c|}
\hline$<10$ years & $3(20)$ & $3(20)$ & $6(60)$ & \multirow{2}{*}{5.625} & \multirow{2}{*}{$0.06 \mathrm{NS}$} \\
\hline$>10$ years & $0(0)$ & $3(100)$ & $0(0)$ & & \\
\hline
\end{tabular}

Table 5: Comparison of candidal carriage among non diabetics according to gender.

\begin{tabular}{|c|c|c|c|c|c|}
\hline & Mild & Moderate & Severe & & \\
\hline male & $6(40)$ & $0(0)$ & $0(0)$ & 6.67 & $0.017($ sig $)$ \\
\hline female & $3(20)$ & $6(40)$ & $0(0)$ & & \\
\hline
\end{tabular}

Table 6: Candidal carriage according to the glycated levels among diabetic patients.

\begin{tabular}{|c|c|c|c|c|c|}
\hline Controlled & $0(0)$ & $3(100)$ & $0(0)$ & 5.625 & 0.060 NS \\
\hline Uncontrolled & $3(25)$ & $3(25)$ & $6(50)$ & & \\
\hline
\end{tabular}

Uncontrolled diabetes: $>7 \%$

Controlled diabetes: $<7 \%$

Table 7: Usage of mouthwash for 3 weeks.

\begin{tabular}{|l|c|c|c|c|l|l|}
\hline & Nil & Mild & Moderate & Severe & & \\
\hline Baseline & $0(0)$ & $3(20)$ & $6(40)$ & $6(40)$ & \multirow{2}{*}{22} & \multirow{2}{*}{$0.000(\mathrm{sig})$} \\
\hline 3 weeks & $9(60)$ & $6(40)$ & $0(0)$ & $0(0)$ & & \\
\hline
\end{tabular}

Table 8: Usage of mouthwash for 3 weeks.

\begin{tabular}{|c|c|c|c|c|}
\hline \multicolumn{5}{|c|}{$\begin{array}{c}\text { Comparison of Candidal Carriage between Baseline to } 3 \text { weeks } \\
\text { among Non-Diabetic patients }\end{array}$} \\
\hline & Nil & Mild & Moderate & Severe \\
\hline Baseline & $0(0)$ & $9(60)$ & $6(40)$ & $0(0)$ \\
\hline 3 weeks & $9(60)$ & $6(40)$ & $0(0)$ & $0(0)$ \\
\hline
\end{tabular}

Table 9: Effect of cinnamon mouthwash after stoppage.

\begin{tabular}{|c|c|c|c|c|c|c|}
\multicolumn{7}{|c|}{ Comparison of Candidal Carriage between Baseline to 4 weeks } \\
among Diabetics \\
\hline & Nil & Mild & Moderate & Severe & & \\
\hline Baseline & $0(0)$ & $3(20)$ & $6(40)$ & $6(40)$ & 20 & $0.00($ sig) \\
\hline 3 weeks & $0(0)$ & $15(100)$ & $0(0)$ & $0(0)$ & & \\
\hline
\end{tabular}

Table 10: Effect of cinnamon mouthwash after stoppage.

\begin{tabular}{|c|c|c|c|c|c|c|}
\hline \multicolumn{7}{|c|}{ Comparison of Candidal Carriage between Baseline to 4 weeks } \\
among Non-Diabetic Patients \\
\hline & Nil & Mild & Moderate & Severe & & \\
\hline Baseline & $0(0)$ & $9(60)$ & $6(40)$ & $0(0)$ & \multirow{2}{*}{20} & \multirow{2}{*}{$0.00(\mathrm{sig})$} \\
\hline 3 weeks & $0(0)$ & $15(100)$ & $0(0)$ & $0(0)$ & & \\
\hline
\end{tabular}

\section{Discussion}

Candida is opportunistic pathogens that can cause disease in host who are compromised by underlying local or systemic pathological processes. Changes in the cellular and humoral immune response may allow different species such as Candida to colonize the sub gingival environment. It has been reported that the proportion of yeast in the periodontal pocket is similar to some bacterial periodonto pathogens suggesting a possible role of Candida in the pathogenesis of the disease. Studies report that candida albicans carriage and density are increased in the oral cavities of diabetic patients and that yeasts are elevated in the periodontal pocket of diabetic patients. In this study also prevalence of candida was more in the diabetic than non diabetics. Candida is 
the most common yeast found in the oral cavity. Existing mainly in two morphologic forms Budding yeast (blastphore innocuous) and Hyphal (responsible for pathogenesis) the adhesion of the C. albicans to buccal epithelial cells have been reported and the common sites of colonization are buccal mucusa, dorsum of the tongue, tonsillar region. Hence exfoliative cytology was carried out in this study which helped in morphologic identification. Commonly used method are culture and bio chemical tests, which is more time consuming and expensive. Exfoliative cytology proved to be a useful tool to identify the organism. Chronic periodontitis patients with diabetes showed increased conversion of yeast to hyphal forms but this technique may not be useful to differentiate other species of candida for which molecular techniques are required. Most of studies have found gender and sex to effect the candidal carriage females exhibited > males. But in this study no significance was observed. In some studies it has been seen that Individuals over the age of 40 exhibited increased levels of candidal infections compared to younger patients [7]. In this study age also did not affect the carriage which is in agreement with B Pallavan et al. [5] who observed that factors such as age, sex, duration of diabetes did not have any relation with degree of oral candidal carriage Present study patients with well controlled diabetes HbA1c $<6$ compared to subjects with poor diabetic control (HbA1C $>9$ ) candidal infections were more but not statistically significant and this is in agreement with other studies such as Mubarak et al. [7] and LV H Hill et al. [8] Cinnamon in addition to its popularity as a spice has been found to have medicinal properties such as anti-bacterial, anti-fungal, anti-oxidant [9]. As fungi is also found to play a role in the pathogenesis of periodontitis as well as oral lesions in diabetics, cinnamon's role as anti-fungal has been explored in this study. It was used for 3 weeks by both the groups and evaluation was done at the end of 1 week after the stoppage of the mouthwash. Till date no such studies have been reported in this regard. There was a significant reduction in candida from the baseline to 3 weeks in both the groups with more significant result groups in diabetic group with periodontitis 1 week after stoppage. It was seen that even though the candida had decreased there was a tendency of the organisms to recolonize so, it was effective in the severe cases. There was no adverse effects reported, but when evaluated regarding the acceptability of the mouthwash based on the Hedonic scale [10], reported moderate satisfaction. Hence more research should be done to improve the palatability of the mouthwash and to check the long term benefit of the effect of cinnamon mouthwash on Candida albicans.

\section{Conclusion}

The treatment for periodontal disease include scaling, root planning with proper oral hygiene but it may fail to eliminate reservoirs of infectious organisms or the appearance of super infecting pathogens like Candida species Anti-fungal can be used but most of these organisms are resistant to present anti-fungal and anti- microbial. So, it is necessary to seek new anti-fungal agents which can cause disruption or destruction of biofilms and which are effective in isolates that express resistance. Plants have been used in medicine for a long time as they are economic, easily available and applicable in various diseases. One such herb is cinnamon. The results of this study show that cinnamon could be a promising alternative anti-fungal.

\section{References}

1. Mohammad M Hammad, Azmi MG Darwazeh, Majdy M Idrees (2013) The effect of glycemic control on Candida colonization of the tongue and the subgingival plaque in patients with type II diabetes and periodontitis. Oral Surg Oral Med Oral Pathol Oral Radiol 116(3): 321326.

2. Casqueiro J, Alves C (2012) Infections in patients with diabetes mellitus: A review of pathogenesis; Indian J Endocrinol Metab 16(1): S27-S36.

3. Canabarro A, Valle C, Farias MR, Santos FB, Lazera M, et al. (2013) Association of subgingival colonization of Candida albicans and other yeasts with severity of chronic periodontitis. J Periodontal Res 48(4): 428-432.

4. Raaz K Maheshwari, A K Chauhan, Ayushi Gupta, Shobha Sharma (2013) Cinnamon: an imperative spice for human comfort. International journal of pharmaceutical research and bio-science 2(5): 131-145.

5. Pallavan B, Ramesh V, Dhanasekaran BP, Oza N, Indu S, et al. (2014) Comparison and correlation of candidal colonization in diabetic patients and normal individuals. J Diabetes Metab Disord 13: 66.

6. HMohamedSham Shihabudeen, DHansi Priscilla, KavithaThirumurugan (2013) Cinnamon extract inhibits a-glucosidase activity and dampens postprandial glucose excursion in diabetic rats. Nutr Metab (Lond) 8(1): 46.

7. Al Mubarak S, Robert AA, Baskaradoss JK, Al Zoman K, Al Sohail A, et al. (2013) The prevalence of oral Candida infections in periodontitis patients with type 2 diabetes mellitus. J Infect Public Health 6(4): 296301.

8. L V Hill, M H Tan, L H Pereira, J AEmbil (1989) Association of oral candidiasis with diabetic control. J ClinPathol 42(5): 502-505.

9. Ulbricht C1, Seamon E, Windsor RC, Armbruester N, Bryan JK, et al. (2011) An evidence-based systematic review of cinnamon (Cinnamomum spp.) by the Natural Standard Research Collaboration. J Diet Suppl 8(4): 378-454.

10. Bhavana Sujana Mulk, Rajalakshmi Chintamaneni, Anuradha Chennupati, Prashant Nahar, Rattaiah Setty Chaluvadi, et al. (2016) Evaluation of Antifungal Efficacy of Ethanolic Crude Lawsone and Listerine Mouthwash in Uncontrolled Diabetics and Denture Wearers A Randomized Clinical Trial. J Clin Diagn Res 10(6): ZC90-ZC95. 
This work is licensed under Creative Commons Attribution 4.0 License DOI: 10.19080/ADOH.2018.08.555728

\section{Your next submission with Juniper Publishers} will reach you the below assets

- Quality Editorial service

- Swift Peer Review

- Reprints availability

- E-prints Service

- Manuscript Podcast for convenient understanding

- Global attainment for your research

- Manuscript accessibility in different formats

( Pdf, E-pub, Full Text, Audio)

- Unceasing customer service

Track the below URL for one-step submission https://juniperpublishers.com/online-submission.php 